\title{
Group Dynamic Assessment (G-DA): The Case for the Development of Control over the Past Tense
}

\author{
Ehsan Mehri (Corresponding Author) \\ Dept. of English Language and Literature, Faculty of Humanities, Arak University \\ Arak 38156-8-8349, Iran \\ E-mail: ehsan.mehri.work@gmail.com \\ Majid Amerian \\ Dept. of English Language and Literature, Faculty of Humanities, Arak University \\ Arak 38156-8-8349, PO. Box: 879, Iran \\ E-mail: m-amerian@araku.ac.ir
}

Received: 06-01-2015

Published: 01-09- 2015
Accepted: 05-03- 2015

doi:10.7575/aiac.ijalel.v.4n.5p.11
Advance Access Published: April 2015

URL: http://dx.doi.org/10.7575/aiac.ijalel.v.4n.5p.11

\begin{abstract}
The introduction of dynamic assessment within sociocultural theory opened a new door toward looking at the relationship between the teaching and assessment. The dialectic relationship between the two processes provides previously unfound information regarding the assessment and the development of the learners. However, the implementation of the interactionist dynamic assessment has carried some difficulties in class in general and the groups in particular. The current study tries to address the effect of group dynamic assessment on the development of the control over the past tense; therefore, it is two-folded in the aim. Not only does it work as a practical sample of group dynamic assessment in class, but also it seeks to analyze its effect on the development of control over the past tense. To this end, three learners at the levels of elementary, low-intermediate, and intermediate general proficiency were asked to read a novel and retell the story. The dynamic intervention provided by the teacher during the story retelling was later evaluated in the transcendence tasks of writing. The Friedman test indicated that the three learners had significant development in their control over the past tense in their writing. Moreover, the qualitative analysis of the interactions suggests that the learners changed their role from the mere receivers of the teacher's mediator into the active providers of mediation to other group members. Also, they developed their understanding of the concept of the past tense through implementing it in transcendence tasks of writing.
\end{abstract}

Keywords: Sociocultural theory; dynamic assessment; group dynamic assessment; zone of proximal development; interaction

\section{Introduction: The Gears of Sociocultural Theory}

The zone of proximal development (henceforth ZPD) as a predominantly sociocultural theory specific concept of development functions as the foundation of social interaction. According to Lantolf (2000), ZPD is a site where the social form of mediation happens. The sociality of such an opportunity brings about at least two individuals in the primary levels of development in order to provide an interactional mood for the development of the concept in the course of interaction. Each mind has certain capabilities and store of knowledge from their past, which is the backbone of the present interactional situation, to step-by-step construct the immediate future of the development of mind. The past-to-present actual level of development (Lantolf and Poehner, 2004) sets the scene for the present-to-future potentiality for development. To fill in the gap between these two levels, purposeful critical interaction is required. As a result, the development of the individual in the course of interaction with a more capable person through mediation or scaffolding happens when both minds move toward the construction of the new knowledge. The construction zone (Newman et al., 1989) is actually what happens in ZPD, where the development happens. It is the interactional opportunity where teacher-student/expert-novice struggle for the activation of emerging abilities of students mostly.

On one side of the interaction, the teacher provides the contingent instructional mediation to the needs of the student (Amerian and Mehri, 2014). The mediation works within the ZPD of the student. Actually, the supportive condition provided by the teacher sets the scene for the student to extend his skill and knowledge in the field of study (Donato, 1994). When the potential development is activated, the constructive mood merges the learning-development line as a dialectic unity. That is, not only the potential development of the person strengthens the actual level of development, but also, they, all in all, support the next developmental stages for the learner.

On the other side of the interaction, the learner has to struggle responsibly for the development of his own abilities when working with the mediator. The struggle assists the learner to develop his ZPD through resolving the tension between the actual level of development and the demands of the task. According to Newman et al. (1989), the resolving of the tension must be established via coherence between the actions of the learner and the teacher's speech. The 
learner's knowledge of what of the task is not necessary in the establishment of the coherence, but the how of the task, that is the actual realization of the knowledge, constructs it.

The way the interaction can manifest development should be sensitive to the actual and potential capabilities of the learner. That is, the amount of mediation and scaffolded instruction has to be initiated from the most minimum level of implicitness to the most maximum level of explicitness (Aljaafreh and Lantolf, 1994). The less the learner needs mediation, the wider potentiality it could be estimated the learner has, since the potential level of development of the learner, as well as his actual level, so much strengthened and ready, will be activated via very minimum mediation. Chaiklin (2003) believes that the size of the ZPD means the amount of learner's gain from mediation beyond independent problem solving. Furthermore, this examination can help the teacher or the researcher to examine the size of the learner's ZPD for assessment and instruction in the process of problem solving.

To conceptualize the ZPD in summary, it could be mentioned that the ZPD is a task specific, open-ended, intersubjective problem solving activity which assists the emergent abilities of the learner for higher development and learning. However, the definition should not be generally implemented for all the individuals. The concept should not divert the teachers and examiners toward ignoring the actual level. Moreover, those who have a narrow size of actual level of development but a wide zone of potential development could function differently from those who have a wide size of actual level of development but a narrow size of potential development. (Mehri and Amerian, under review)

\section{Moving toward Dynamic Assessment}

The examination of the ZPD happens when the teacher/examiner can evaluate where the learner stands primarily at his actual level of development. As a result, not only the developmental interaction should be established, but also the assessment of the individual both for the developmentality and actuality of the learner needs consideration. This means that instruction and assessment are both two sides of the same process. To merge them means to permeate into the core of the process. Therefore, dynamic assessment (henceafter DA) as a merged concept of assessment and teaching can assist both the teachers and examiners to evaluate the ZPD of the individuals. However, Mehri and Amerian (under review) believe that the concept of DA should be implemented in regard to the aim the practitioner is bearing in mind. If the focus of the DA is on the assessment part of the process, hence the Dynamic Assessment and Teaching (DAT) is required. On the other hand, if the focus of the DA is on the teaching part of the process, the Dynamic Teaching and Assessment (DTA) is required. Of course, the mere focus of the process on teaching or assessment does not mean that the process lacks either of them. The word "dynamic" points to the dialectic relationship between assessment and teaching at the same time.

According to Poehner and Lantolf (2010) the "jointed activity intended to reveal a learner's ZPD and the provision of mediation to support continued development are fully integrated in DA." Poehner (2005) defines it as "assessment and instruction... dialectically integrated as the means to move toward an always emergent (i.e., dynamic) future" (p.20). In the similar vein, Haywood and Lidz (2007 cited in Birjandi et al., 2013) "explain that DA is an interactive procedure that systematically and objectively measures the degree of change that occurs in response to cues, strategies, feedback, or task conditions that are introduced during testing" (p. 74). All in all, the main feature in all of the definitions of DA is that the concept is process oriented, it is interactive, and finally it is sensitive to the ZPD of the individuals.

Despite the features of the DA, there are certain elements in the process that have to be considered. First of all, the process needs mediation. The presence of a mediator challenges the learner through supportive intervention to develop the functioning of the individual. The process makes the learner aware of the bots and bolts of the field, not only of the knowledge of what is conveyed to the learner, but also of the knowledge of how it is made significant for him. In other words, the learner is metacognitively aware of how the problem is resolved. But the mere accomplishment of the problem in the jointed collaborative dialogue cannot be a sign of development for the learner. The implementation of the transcended tasks puts the learner under the more difficult situation in order to assess the level of independent functioning and the degree of development in comparison with the beginning of the program (Kozulin, 2011). Therefore, the examiner is continuously assessing and teaching the concepts of the field of the study in a collaborative dialectic manner.

DA fundamentally provides two bits of information. The individual's performance in the dialectic jointed activity, and the amount of benefit the individual can receive from the assistance provided in the process of the task of the test as well as the transference of the abilities gained through the interaction (ibid). Strenberg and Grigenko (2002) believe that DA is

... a procedure whose outcome takes into account the results of an intervention. In this intervention, the examiner teaches the examinee how to perform better on individual items or on the test as a whole. The final score may be a learning score representing the difference between pretest (before learning) and posttest (after learning) scores, or it may be the score on the posttest considered alone (p. vii).

Lantolf and Poehner (2004) divide DA in two general realizations. In the interactionist DA, the mediation is actually negotiated between the students and the teacher in the dialogue. The mediator is sensitive to the immediate needs of the learner and provides opportunity for the development of the potentialities when necessary. On the other hand, in the interventionist DA, there are certain scripted prompts that are arranged hierarchically and are administered in order to develop the potentiality of the learner. Therefore, the mediator is not free to respond to the needs of the learners. While 
the interactionist DA centers attention on the interaction and qualitative approach of assessment, the interventionist DA tends toward quantitative assessment (Poehner, 2008).

The interactionist DA bases the mediation on the responsiveness of the learner and his immediate needs. In other words, the "feedback is emergent rather than preplanned and learning is interpreted rather than measured"(Tajeddin and Tayebipour, 2012, p. 90). Also, the problems are resolved and targeted through dialogic enquiry (Wells, 1999). The development of the individual happens in the incidental interaction. Therefore, the interaction requires a highly skilled patient mediator and the approach seems not to be implemented for a large number of students (Zhang, 2013). However, Poehner (2009) uses the DA in groups (G-DA), believing that the group is not an opportunity for the performance of the individuals, but a social context in which all the members struggle collaboratively to extend the capabilities of their own and that of the others as a whole group. The teacher, on the other hand, must engage the whole group in the process of G-DA.

Poehner (ibid) divides the participants of interaction in G-DA to that of primary interactants and secondary ones. When the teacher and the learner are engaged in the process of the dialogue, the result of which could be a response to the learners' source of difficulty, they play the roles of primary interactants. However, other participants of the group who are eavesdropping warily on the primary interactants play the role of secondary interactants. They also benefit from the interaction in their own specific way for their source of knowledge and problems in the field of study. The roles of the participants of the group may change simultaneously and fluidly. To categorize this, Poehner classifies the changing role of the interactants as cumulative and concurrent. In the cumulative form, the teacher provides mediation to individuals and each member takes the role of primary interactants, and then shifts to another respectively. The whole series of exchanges aim at developing the group as a whole. In concurrent G-DA, however, the teacher provides the mediation to an individual, but the course of interaction shifts between the individuals, that is, there is not any specific primary interactants. In other words, "cumulative G-DA attempts to move the group forward through co-constructing ZPDs with individuals, but concurrent G-DA supports the development of each individual by working within the group's ZPD" (Poehner, 2009, p.478).

The interactions, whether provided to individuals or to groups, cannot lead to fruitful development, since the tuning of the interaction between the teacher and the ZPD of the individuals and groups might be roughly administered. In addition, the grouping of the individuals cannot be randomly set. Hill and Sabet (2009) maintain that the development of the most competent learners might bring about the ceiling effect, and the least competent individuals might not gain successful mediation when they are grouped together. Moreover, according to Poehner and Lantolf (2005), the ZPDs can both have progress and regression. This is highly possible in the G-DA where the successful interaction tuned to the ZPD of the individuals, or the group, might not be always at work, though the quality of interaction could make a different outcome (Poehner, 2008).

Vygotsky's theory of human conscious activity maintained that the development of consciousness is always at the support of external auxiliary tools. The formation of human consciousness is primarily external and social, and then internal and individual. Therefore, the engagement of the individuals in the social activities within ZPD connotes the purposeful, conscious, and deliberate effort in order to bring about modification and/or development in the higher mental functioning. Aljaafreh and Lantolf (1994) believe that to promote development, the concepts have to be foregrounded on the level of conscious analysis of the individuals. This puts the process at the control and under the responsibility of the person to be internalized through performance.

The control over the tools and concepts to be internalized were generalized by Vygotsky (1986) across domains via metacognition. In other words, individuals have to be self-conscious to develop the proper concept within their mental functioning. The idea of meta-cognition plays a central role in both ZPD and DA related research and practice. Long (1990) takes the idea of being aware and conscious in language learning as an adequate explanation for acquiring forms in a second language. However, the idea is not self-evident, since the interplay between conscious and subconscious learning has some sense of validity within second language learning theories. However, SCT favors the metacognitive aspect of learning. Research in DA area has realized the idea through metalinguistic knowledge of the learners (Poehner, 2008; 2009).

\section{The study}

The current study was conducted as an extra-curricular course for 3 learners of English as a foreign language. The participants were required to take part in the course voluntarily. The course focused on the reading and speaking of the learners, in that the learners were suggested to study Hemingway's A Farewell to Arms novel for the reading part of the course.

Before the start of the main study, all the three participants were tested for their general proficiency level through the Oxford Placement Test. The results were elementary for Alex (with the score of 27 out of 60), low intermediate for Mathew (with the score of 33 out of 60), and intermediate for Anthony (with the score of 40 out of 60) (all pseudonyms). The participants were males who had passed several terms of language learning. They were all highly motivated to learn and increase their level of proficiency in the foreign language. They previously had the experience of reading literary texts like short stories, novelettes, and some poetry, though the materials were used as a side source for their language learning.

This course was primary a novel reading course as well as focusing on the retelling and interpreting of the literary work. The study was conducted in 5 sessions. Each session lasted about 45 minutes. The participants were required to read 
some chapters of the novel informed by the instructor before attending the class (the number of chapters were equal in each session). The process was explained to the learners that they have to retell the parts they had studied at the beginning of the class, and then present their interpretation of those parts to the class through interaction with other peers and the instructor of the course. And finally, they had to transfer their retelling of the novel to a writing activity bearing in mind the interaction they had in that session.

So far as the theoretical principles of the DA are concerned, the study aimed at benefitting from the interactionist approach of DA, in that the development and assessment of the learners were responded on the spot. However, the nature of the course relied on the use of the past tense for retelling the novel. The participants were informed that for retelling the story they had studied, they needed to use the simple past tense for the report of the events. However, the point could be manipulated interchangeably to other tenses in the interpretation phase of each session. The case for the transcendence of the activity was assured through writing the retelling section of the interaction in a writing activity. This was more of a challenge and assessment of the participants if they could transfer the control of the past tense to other more abstract activities. Therefore, the study aimed at seeking into the development of control over the past tense in story retelling due to the incorporation of DA.

\section{Results}

In this article, it is attempted to focus on those mediated interactions which were aimed at the use of the past tense for the retelling sections. Alex was an elementary English learner. He was highly motivated in learning English as he mentioned before the course started. He acknowledged that he needed some modification in his grammar as well as speaking accuracy. The following extract is from the first session.

1 Alex: it's about world...world war one

2 T: uhum.

3 Alex: and it's the story of a soldier that go...the story of an American soldier that go to the....

4 T: sorry, that...?

5 Alex: That want, want to take part in the, in the war and he...he became the member...a member of the army of Italian...Italy...

6 T: ok, there is a problem in the tense of verbs.

7 Alex: he memebered...he member...he take part in the army of Italy

8 T: he take part?

$9 \quad$ Alex: he take part in the army

10 Anthony: took part

11 Alex: took part?

12 Anthony: he took part in the army

13 Alex: oh yes, he took part

Alex starts the retelling of the story; however, he has a problem in 3 when he misses the use of the past tense for the report of the events. The teacher intervenes through prompting him that there is a problem in the sentence. In 5, Alex attempts once again to restate his sentence. The failure to modify the tense might be due to not realizing the source of the problem; therefore, in 6 the teacher uses a more explicit mediation, revealing the source of the problem. However, Alex mistakenly changes another word to the past tense. In 8, the teacher uses a more explicit mediation, mentioning the problem itself. Despite this, Alex is still confused what the problem is. Actually, the level of control over the past tense might be due to the lack of knowledge of what the past form of "take part" is. In the group mediation, other members, being contributive to the goals of the interaction, intervene in order to modify the problem. They sometimes play the role of the peer assistant in the problem solving of the other members of the group. Anthony, in 10, seeing that Alex cannot benefit from the mediation, intervenes and provides the correct form of past tense. After that, Alex wonders what "took part" is. Then, Anthony explicitly puts the past form in Alex's problematic sentence, after which, Alex realizes that the past form of the "take part" is "took part". The interjection, "oh" functions like a realization toward the accomplishment of the task.

Mathew, a low intermediate English learner, was also highly motivated. He had studied English for 2 years. He believed that he needed more practice in speaking fluently. Moreover, he insisted that he enjoyed stories and the discussion over literary works. The following extract is again about the interaction over the use of the past tense in reporting the events.

14 T: could you tell me a summary of what happened in the first eight chapters?

15 Mathew: you know, mostly, it was, e, the, there was some feelings.

16 T: sorry again?

17 Mathew: there were some feelings

18 T: aha.

In this extract, the teacher triggers Mathew to report the events through setting questions. Mathew in 15 starts the report, and he follows the past tense rule of reporting, however, he has a problem regarding the use of the singular or plural match between the verb and the object in the sentence "there was some feelings". The teacher mediated this implicitly, in 16 to convey that there is a problem in that sentence. Mathew, as a result, swiftly modified the problem, 
benefiting from the mediation, and changed the singular "to be" verb to the plural form. Now, the modification could be the effect of the previous interaction with Alex, in that the teacher focused on the use of the past form. Therefore, Mathew might be a little more conscious over the tense of the verbs, though he needed very implicit mediation for the development of control over the tense.

Anthony, an intermediate English learner, attended English classes for over 3 years. He had a lot of experience of discussions, interactions, conversations with native speakers. He was also highly motivated to attend this course, mentioning that he needed more self-confidence in speaking, and negotiating his ideas. He was very contributive to the course of interaction in the class, and dedicated his time and energy to have a fruitful outcome.

19 Anthony: I think after a while they start...

20 T: sorry, sorry, would you, they?

21 Anthony: after a while ..

22 T: aha. They...?

23 Anthony: they also, specially that boy that guy fell in love with that girl.

In 19, Anthony attempts to report the events, but he uses the present tense for "start", when the teacher intervenes to mediate implicitly that there is a problem in the sentence, Anthony repeats the sentence over again, hesitating for some moments to reflect over the sentence in 21 . The teacher, on the other hand, in 22 , tries to prompts him to continue. However, in 23, Anthony uses the strategy of rephrasing his report of events, to another question, letting go of the problem. He strategically circumvented what he intended to say, though previously he had experience of what the focus of the teacher's intervention was.

For the sake of space, we move to the third session of the course. In the second session, there were some meditational moves over the use of the past tense. To evidence the changes through the session, the description of the interaction in the third session can show the changes in the individuals more explicitly. Alex has improved in the third session, in receiving mediation. He can manage the control over the past tense of the verbs in retelling the story events. Although he still has certain problems in the use of the past tense, he can benefit from the less explicit mediation. The following extract evidences the point.

24 Alex: after three weeks leave, he wanted to go to the war or either, or go to the...go with his wife but she didn't answer for enjoyment. When he go to the hospital...

25 T: ok Alex, is the tense of your verbs ok?

26 Alex: yeah he went...

In this extract, Alex benefited from the mediation in 25 quickly. He swiftly changed the tense of the verb to the past without wondering which verb is referred to. Actually he is getting more conscious. Anthony and Mathew had almost no problem in using the past tense. The very few occasions when it happened to them, upon the change of teacher's facial expression, they could quickly change the tense to the correct form. They were highly conscious of the use of past tense in reporting events of the story. However, as they became more conscious, they changed the role from their own problem solving situation to assist the other member of the group, Alex, in having more control on the past tense.

27 Alex: I think naturally when he feel love with someone.

28 T: sorry when you..

29 Alex: feel.

30 T: feel in love

31 Mathew: when you fall in love.

32 Anthony: yes when you feel the love.

33 Mathew: no he wants to say fall in love.

34 Anthony: feel love.fall in love.

35 Mathew: when you are in love.

36 Alex: fall in love.

37 T: when you fall in love. And in the story you should say?

38 Alex: whey he fell in love.

39 T: right.

In 27, Alex mistakenly used both the incorrect verb and the tense. Not only did he have a problem in the phrasal verb of "fall in love", but also he could not change the tense to the past form. Upon the mediation of the teacher, an implicit one, Alex could not realize what the problem is. Actually due to the twofold layer of the problem, Alex, as a matter of being conscious over the verbs, just picked the verb to be problematic. When the teacher in 30 , stated that the "feel in love" has a problem, Mathew intervened in the interaction to correct the phrasal verb, referring to the first layer of the problem. Anthony, also on his part, tried to modify what Alex wanted to say, that is, putting at work his usual strategy of paraphrasing the ideas, and changed the sentence in 32 to "yes when you feel the love". However, Mathew, in 33 insists on the original idea of Alex, believing that he intends to use the "fall in love" collocation. Anthony supports this and then, Alex reemerges in the course of interaction, taking the role of the primary interactant, after being in the 
background, and picks the "fall in love" collocation. Now that the first layer of the problem is resolved, the teacher refers to the second layer of the problem that is the past tense. He attempts to rejoins the correct collocation to the main structure of the retelling phase of the activity in 37 . Alex correctly benefits the mediation, and changes the tense to the past form.

In the fifth session, all the members have benefited from the mediation. Not only have Mathew and Anthony changed the degree of control over the past tense, but also they tried several times to intervene in the course of interaction between the teacher and Alex to increase the level of Alex's control over the problem. The changing role of the primary interactant and secondary interactant for Alex let him be an observer sometimes on the process of his problem solving in the hands of Mathew and Anthony. Actually, the imitation of forms of interactional behavior between the teacher and his group-mates provided the opportunity for him to increase his potential development. However, even Alex could enhance his level of control to grasp the role of intervener, like Anthony and Mathew. This is again in line with Vygotsky's emphasis on imitation as a way of developing the potentiality of individuals. The following extract illustrates the role of Alex as an assistant group-member in contributing to the problem of other group-members in the fifth session.

40 Anthony: Miss Ferguson was very angry at Mr. Henry because he has made his friend pregnant.

$41 \quad \mathrm{~T}$ : sorry, he has made his friend pregnant?

42 Anthony: he has made her friend pregnant.

$43 \quad \mathrm{~T}$ : sorry is he has made her friend pregnant correct?

44 Anthony: he has made her friend pregnant.

$45 \mathrm{~T}$ : is the tense ok.

46 Alex: no he had made.

$47 \quad$ T: yes he had made. And why do you have to say in that tense?

48 Anthony: yes because it is in the past. He had made his friend pregnant.

49 Mathew: her friend.

50 T: sorry?

51 Mathew: he had made her friend pregnant.

52 Anthony: oh her friend pregnant.

In this extract, Anthony has got a problem regarding the use of the past tense in reporting events. Although Anthony and Mathew had very rare problems in this area, this problem happened in Anthony's long turn of retelling the story. In 40, Anthony could not change the tense from the present perfect to the past perfect. The teacher mediated him implicitly in 41. However, Anthony could not realize what the problem is, despite his being conscious in the previous sessions upon facing the most implicit mediation and his assistance for the other group members. The teacher provided a more explicit mediation in 43, to which Anthony could not respond beneficially. As a result, in 46 Alex intervened in the modification of the tense, since the teacher in 45 mentioned the source of the problem. Alex could function like Mathew and Anthony as an assistant for solving problems, taking the primary interactant from Anthony who previously had taken the same role from Alex. This actually resembles the development of the role changing so far as it is related to the process of imitation of roles from Alex's part. And when in 47 the teacher confirms Alex's intervention and asks why this is the case, Anthony provides the answer in that it should be in the past form. However, Anthony makes another problem in modifying the tense of the verb, in that he mistakenly changes the female possessive pronoun to that of a male. Despite that, Mathew intervenes here to provide the point. This shows that the members of the group are active observers of the course of interaction, not merely passive peer learners in the group. This is of course due to their contributive attitude toward learning and participating in the activity, as Poehner (2009) mentions that the participants and learners of the DA should have positive and active attitude toward the activity in order to have their potential level developed.

To have developmental validity, it is suggested that the DA activities should have the element of transfer/transcendence in their main body (Kozulin, 2011). This was realized through writing, in that, the participants were asked to write the retelling section of each session. The process of transfer and its evaluation was done through counting the number of words, the number of the past forms used in the retelling part of their writing, and the number of mistakes.

Table 1. The analysis of verbs in Anthony's summary writing

\begin{tabular}{|c|c|c|c|c|c|}
\hline Text features & 1 & 2 & 3 & 4 & 5 \\
\hline Word counts & 167 & 220 & 170 & 251 & 227 \\
\hline Verbs used & 24 & 25 & 21 & 35 & 36 \\
\hline Correct past forms & 19 & 20 & 18 & 32 & 33 \\
\hline Mistakes & 5 & 5 & 3 & 3 & 3 \\
\hline Percentage of mistakes & 20.83 & 20 & 14.28 & 8.57 & 8.33 \\
\hline
\end{tabular}


Table 2. The analysis of verbs in Mathew's summary writing

\begin{tabular}{lccccc}
\hline \multicolumn{1}{l}{ Sessions } & 1 & 2 & 3 & 4 & 5 \\
Text features & & 152 & 123 & 132 & 150 \\
\hline Word counts & 114 & 21 & 13 & 20 & 10 \\
\hline Verbs used & 14 & 19 & 12 & 18 & 10 \\
\hline Correct past forms & 8 & 3 & 1 & 2 & 0 \\
\hline Mistakes & 6 & 14.28 & 7.69 & 10 & 0 \\
\hline Percentage of mistakes & 42.85 & &
\end{tabular}

Table 3. Analysis of verbs in Alex's summary writing

\begin{tabular}{|c|c|c|c|c|c|}
\hline $\begin{array}{l}\text { Sessions } \\
\text { Text features }\end{array}$ & 1 & 2 & 3 & 4 & 5 \\
\hline Word counts & 176 & 183 & 222 & 220 & 275 \\
\hline Verbs used & 21 & 21 & 27 & 27 & 37 \\
\hline Correct past forms & 4 & 14 & 22 & 22 & 32 \\
\hline Mistakes & 17 & 7 & 5 & 5 & 5 \\
\hline Percentage of mistakes & 80.95 & 33.33 & 18.51 & 18.51 & 13.51 \\
\hline
\end{tabular}

The statistical significance of the decreasing trend in the number of mistakes was investigated through calculating the Friedman test. The test was conducted to evaluate differences in mistakes for Writing 1 (Median= 6), for Writing 2 $($ Median= 5) for Writing 3 (Median= 3), for Writing 4 (Median= 3) and for Writing 5 (Median= 3). The test was significant $X^{2}(4, N=3)=11.216, p=.024$, which indicates strong differences among the number of mistakes in five writings.

There are three points about the above tables. First of all, in the three learners' texts, the number of the words in each session increases except the second session, especially for Anthony and Mathew. The number of words in the second session for these two individuals is more than the third session's. In other words, the number of words in the second session for Anthony and Mathew are 220 and 152 respectively, which is more than their third session which are 170 and 123. However, Alex has written more in each session in comparison with the previous session(s). If we ignore the second session for Anthony and Mathew so far as the number of the words is concerned, it is revealed that, they, too, have increased the number of summary writing in each session. The problem for the second session might be due to the large number of events happening in the chapters retold in that session. But, one needs reexamining the texts too. The more they had been engaged in the retelling of the story, the more detail they could have written about.

While the number of words for each individual, given the description above, has increased, the number of mistakes so far as the past tense is concerned has decreased interestingly. From the first session to the fifth session, Anthony has had $5,5,3,3,3$ mistakes in the use of past tense for the summary of the events, as it was mediated and realized in the intervention phase of the study. Now, the number of mistakes have decreased all right, however, one has to interpret this result in the light of the fact that the number of the total verb and word counts have increased respectively. In other words, the number of verbs has increased from 24 to 36, and the texts are longer. Moreover, the number of the mistakes is less. The last row in Anthony's table is dedicated to the percentage of the verbs. As it is illustrated there, the percentage of the mistakes in relation to the number of total verbs in each session has decreased, revealing the fact that Anthony has developed more so far as the control over the use of the past tense in writing the summary and/or report of the events in the story is concerned. The same point is true for the other group members. Mathew was able to develop his control over the use of the past tense in writing from having 42.85 percentage of mistakes in the first session to no mistakes in the last session. Alex, also, has developed very significantly, since his percentage of mistakes has been 80.95 in the first session, and this has been reduced to 13.51 in the fifth session of intervention. Although the level development for Alex has been more than Anthony and Mathew, the interpretations should be cautious.

According to De Beer (2002), the idea of the ceiling effect is sometimes at work, when the interpretation of DA intervention is at work. This is because the development of the elementary learners is more significant than the development of the more advanced learners. However, the degree of the development should not be understood as the more ability of the learner. This is the quantitative aspect of the development. The more advanced learners' minimum quantitative development is qualitatively richer than that of the elementary learners. But the quantitative results could be a signal for the mere developmental aspect of the mental functioning of the learners so far as the ability related construct is concerned. In relation to the above results, Anthony is an intermediate learner, while Alex is an elementary one. Although the reduction of the mistakes for Anthony has been from 20.83 to 8.33 percentages, the range is narrowed in comparison with that of Alex whose reduction of mistakes was from 80.95 to 13.51 .

\section{Discussion}

The interactionist DA has been limited to the one-to-one interactional opportunities for the development of the individuals. Most of the research projects have been in favor of having the intervention phase of the study on one person at a time (Feuerstein et al., 1988; Anton, 2009; Poehner and Lantolf, 2010; Xiaoxiao and Yao, 2010). However, recently there have been some attempts toward conducting group DA in relation to the second language learning and 
development (Poehner, 2009). Moreover, as Lantolf and Yanez-Prieto (2003) have insisted, the group formation provides an opportunity for other learners to benefit from the interactions as a stepping stone for their own development. Bearing in mind Brown and Ferrar's (1999) "community of learners", each learner can behold the role of a primary interactant with the teacher, which can provide him/her firsthand experience and learning potential. The status of a primary interactant does not deprive others from the opportunity of development. Although Alex had several problems and required mediation from the teacher, every now and then, his group peers, Anthony and Mathew, intervened in the process of talk between him and the teacher, to provide their own peer mediation in order to push him toward his potentiality. This was apparent throughout the summary section of the intervention phase of the study. The more capable peers of the group, mostly Anthony, also collaborated with Mathew to provide the stepping stone for the Alex and themselves, to develop in relation to the use of the past tense for the retelling of the events. Actually, according to Petrovsky (1985), when learners have the same goal and are motivated to improve in a collaborative manner, they try not only to use the group as their own opportunity for development, but attempt to develop the group as a whole. The whole group is believed to have responsibility over the problems of his and that of others. The success of others benefits him and vice versa. It is their collectiveness (ibid) that brings about the community of the learners. Their group is not just a physical formation where individuals are set together, but they are dedicated and responsible to intervene for mediation whenever they see it appropriate. Also, the teacher was not the only mediator in the study. According to Walqui (2006), the teacher is not the only source of scaffolding and mediation in the sociocultural related studies. If learners are aware of how and when to scaffolding and inject assistance, this will give benefit to the individual in the need of mediation and provide a reflective condition for the mediator in assessing his own level of control over the point in question.

In order to make learners struggle for development (Poehner and Van Compernolle, 2013), take responsibility for their activity, and reach the construction zone (Newman et al., 1989), the mediation was provided from the most implicit form, and then, when it did not work out, the more explicit forms were negotiated with the learner. However, the interactionist DA required the negotiation of the problems and the degree of confidence and control over the points interacted. The mediator did not merely focus on the past tense, but he emphasized on other unseen problems. However, the past tense, which was the focus of the current study, was mostly interacted. The teacher, upon pinpointing any problems regarding the use of the past tense in reporting the events of the story, provided the most implicit form of mediation. This, on the part of the learners, could not be fruitful at times. The case mostly happened for Alex who had less competence in comparison to his group peers. However, even the more explicit forms could make Alex realize where the problem is, what it is, and how it should be resolved. The interactions between the mediator and Alex as well as Anthony and Mathew provided a conscious mood in the group. It means that in the five DTA sessions, learners realized that the mediation was mostly related to the use of the past tense. Therefore, the more they had the experience of being intervened and mediated by the teacher, the more they realized that the mediations were for the sake of problems in their use of the past tense. Actually, they were form-sensitive to the use of the past tense. In some occasions, this happened in the last sessions mostly, the learners were aware upon being intervened so quickly that they had to modify the tense of their verbs. According to Poehner (2008), the interaction in the ZPD, sets the scene for a purposeful conscious intervention, where the learner bears in mind certain metacognitive awareness in order to develop his control over the points interacted. However, this could be problematic for the less competent learner of the group, Alex. When a certain problem happened in his speech, the teacher mediated from the most implicit form through repeating the sentence with the rising intonation, or question form. Despite his developed control over the past tense in the activity, when several problems happened in his sentences and actually it was not related to the past tense, he mistakenly changed the tense of the past verb. But the intervention of his peers collaboratively made him aware of the other sources of problem. The raising of consciousness of the learners over the point in the intervention session made them sensitive to form. Actually, the repetition of mediation over the past tense made a primary consciousness about this form. And when they were mediated for other problematic areas their secondary consciousness had to struggle to be mediated appropriately. As a result, they needed more explicit mediation for development. If the primary consciousness of their focus on the form was emphasized, they could easily benefit from the mediation with the most implicit form, thus stretching their ZPD and the actual level of development over the use of the past tense. So, the repetition of the mediation over one form can cause the challenge between the primary consciousness of the form and secondary consciousness. The former is actually for the case of emphasis on the learning/development part of the DA, while the latter is a background place for other forms to be mediated.

Vygotsky believes that a very extreme and powerful path of development is imitation (1986). If the learner can imitate the principles of an activity, he is expected to develop his level of control and mental functioning in the given area of capability, thus, internalize it. Of course, the imitation is not that of the mechanic behaviorism. It is actually the realization of the development toward a higher qualitative performance. As it was observed in the study, the beginning sessions of the study were very challenging for Alex. He was repetitively mediated in the primary sessions. The more the mediation was provided, the more he and his peers got conscious of the form. But the point was that, in the middle of the study, his peers, after gaining a certain degree of control over the use of the past tense, tried to mediate Alex in the construction zone. Peers actually changed role from being primary interactants with the teacher, to active mediation providers to others. After a while, in the process of interaction between the teacher and the more capable peers, Alex tried to fulfill the same role as his peers did for him. In the qualitative analysis of this study, it was revealed that Alex tried to provide mediation for Mathew and Anthony in the course of mediation the teacher provided for them. This was of course happening when Alex developed a certain degree of control over the past tense in his story retelling. 
The more he became capable of the activity in hand, the more he could perform the role of the mediator for others. Therefore, the changing roles from a mere benefactor of the mediation to that of the source of mediation happened within his role playing in the group. On the other hand, this was actually in line with the mediating behavior of the teacher. Alex not only tried to change his role within the interaction as a copy of the model from the teacher, but also imitated the behavior of his peers in the course of interaction in the process of mediation.

In studies related to DA in general, and the interactionist in particular, there is a distinguishing element within the field that makes one of the fundamental pillars of DA. Transcendence in interactional studies of Feuerestein et al. (1988), and transfer in DA studies in general have been taken as a serious attempt toward making DA a valid path toward merging assessment and learning. The idea of transfer is to provoke learners to perform their abilities they have developed in the intervention phase to the other related, more complex tasks (Kozulin, 2011). Through this, it could be confirmed that a change has happened in the mental functioning of the learners. Although this has been investigated in the field of second language development on personal tasks, this study has taken the principle of transfer in G-DA. Kozulin (ibid) mentions that there should be a difference between learning potential and cognitive modifiability in DA studies. By learning potential, he refers to the meditational interaction between the learner and the mediator in which the learning is pushed into his ZPD and he is actually at the level of stretching the developmental potentialities. This here and now capability should not be taken for granted as the real potential development. If the learner can transfer the abilities developed in the learning potential phase to another more complex and difficult activity, it could be validated that the learner has some certain cognitive modifiability. In other words, it could be confirmed that the learner has developed certain abilities in the given area of mental functioning and his interrelationships on internal mental systems have been qualitatively developed. The same thing principally happened in our study. The transfer of control over the past tense in retelling the events of the story was realized through the task of writing the events. However, this transfer was not after the several intervention sessions, but it actually was instructed continuously throughout the mediation. There was a twoway-highway in the process of DA, in that, the learners were mediated in each session and then confronted with the transfer task of writing the course of events in the novel. This continuous transfer provides us the opportunity to pursue the course of development of the learners in their other complex tasks on the one hand, and to validate our approach of DA on the other. Moreover, one of the promises of DA is that the source of problems could be pinpointed in the interaction. Although, the intermediate learner of the study, Anthony, could not develop as Alex did, his developmental route was different from his peers. The same case was true for other peers in the group. It means that even though all the learners were benefiting from the same opportunity of mediation at the same time and place, and they could develop their abilities as primary and secondary interactants, they moved through their own developmental routes.

Anthony's source of problem in the learning potential phase of the study was mostly to be conscious about the use of the past tense. He did develop the ability with the implicit forms of mediation but in the transfer of the principles into writing, which is the cognitive modifiability phase, it was realized that the change of the verbs' tenses to the past form was done successfully. However, he had certain problems in the change of the reported speech to the past form. Mathew, also, had the same problem and success. He could change the tense of the verbs occasionally to the past form, but there were several pitfalls in the course of the attempts. Moreover, the last performances in the transfer activity revealed that he is on the edge of having control over the change of the reported speech to the past form. The situation was different for Alex. He had many mistakes and problems in changing the verbs' tense and reported speech. However, the more he gained confidence and ability in the learning potential and cognitive modifiability phases, the more he could get control over the use of the past tense. But he repetitively avoided the use of the reported speech in his transfer tasks. He used the direct speech most of the time. On the other hand, the level of development over the past tense was not complete even in the last transfer case, but it developed significantly.

\section{Conclusion}

Although DA has been fruitful in its practical results, there is still so much vagueness in the process of mediation. What actually happens to the learner, how differently they perform upon facing the DA experience, what type of roles they take in different tasks, and so many other questions have to be investigated both qualitatively and quantitatively. The raising of the consciousness of the learners in this study made them form-sensitive, thus they were primarily conscious about the use of the past tense in their learning potential phase. Their secondary consciousness was at work for other problematic forms. This made a challenge of focus and responsivity to the mediation provided by the teacher. In other words, the mediation targeted to the secondary consciousness problems led the mediator to provide more explicit forms. However, this did not cause impedance for the development of the learners so far as their control over the past tense was concerned. The transfer tasks validated the development of the past tense in a continuous and consistent way. Also, the roles peers accepted in their G-DA changed fluidly in the course of interaction throughout the intervention sessions. The learning potential phase was not only at the service of the interaction between the mediator and the learners, but the imitational development of some learners, like Alex, made them change their roles from a mere benefactor of the mediation and assistance, to that of an active provider of mediation for his peers. Not only did the more competent peers gain confidence when they provided the mediation for their peers, but they also accepted the mediation when other less competent group peers, like Alex, assisted in the same manner. And finally in their transfer cases, they could be targeted as developed learners, with some problems, the source of which could be narrowly explained and described in their performance. 


\section{References}

Aljaafreh, A., \& Lantolf, J. P. (1994). Negative feedback as regulation and second language learning in the zone of proxiam development. Modern Language Journal, 78(4), 465-83.

Amerian, M., \& Mehri, E. (2014). Scaffolding in sociocultural theory: Definition, steps, features, conditions, tools, and effective consideration. Scientific Journal of Review, 3(7), 756-65.

Anton, M. (2009). Dynamic assessment of advanced second language learners. Foreign Language Annals, 42(3), 57698.

Birjandi, P., Estaji, M, \& Deyhim, T. (2013). The impact of dynamic assessment on reading comprehension and metacognitive awareness of reading strategy use in Iranian high school learners. Iranian Journal of Language Testing, $3(2), 60-77$.

Chaiklin, S. (2003). The zone of proximal development in Vygotsky's analysis of learning and instruction. In A. Kozulin, B. Gindis, V. Ageyev, \& S. Miller (Eds.), Vygotsky's educational theory and practice in cultural context (pp. 39-64). Cambridge: Cambridge University Press.

De Beer, M. (2002). The construction and evaluation of a dynamic computerized adaptive test for the measurement of learning potential. Unpublished Doctoral Thesis, University of South Africa.

Donato, R. (1994). Collective scaffolding in second language learning. In J. P. Lantolf and G. Apple (Eds.). Vygotskian approaches to second language research, (pp. 33-56). Norwood, NJ: Albex.

Feuerstein, R., Rand, Y., \& Rynders, E. J. (1988). Don't accept me as I am: Helping retarded people to excel. US: Plenum.

Hill, K., \& Sabet, M. (2009). Dynamic speaking assessment. TESOL Quarterly, 43(3), 537-45.

Kozulin, A. (2011). Learning potential and cognitive modifiability. Assessment in Education: Principles, Policy \& Practice, 18(2), 169-81.

Lantolf, J. P. (2000). Sociocultural theory and second language learning. Oxford: Oxford University Press.

Lantolf, J. P., \& Poehner, M. E. (2004). Dynamic assessment: Bringing the past into the future. Journal of Applied Linguistics, 1(1), 49-76.

Lantolf, J. P., \& Yanez-Prieto, M. C. (2003). Talking yourself into Spanish: The role of private speech in second language learning. Hispania, 86(1), 98-110.

Long, M. (1990). The least a second language acquisition theory needs to explain. TESOL Quarterly, 24(4), 649-66.

Mehri, E., \& Amerian, M. (in process). Challenges to dynamic assessment in second language learning.

Newman, D., Griffin, P., \& Cole, M. (1989). The construction zone: Working for cognitive change in school. Cambridge: Cambridge University Press.

Petrovsky, A. V. (1985). Studies in psychology: The collective and the individual. Moscow: Progress.

Poehner, M. E. (2005). Dynamic assessment of oral proficiency among advanced L2 learners of French. Doctoral Dissertation. The Pennsylvania State University, State College.

Poehner, M. E. (2008). Dynamic assessment: A Vygotskian approach to understanding and promoting second language development. Berlin: Springer Publishing.

Poehner, M. E. (2009). Group dynamic assessment: Mediation for the L2 classroom. TESOL Quarterly, 43(3), 471-91.

Poehner, M. E., \& Lantolf, J. P. (2005). Dynamic assessment in the language classroom. Language Teaching Research, 9(3), 233-65.

Poehner, M. E., \& Lantolf, J. P. (2010). Vygotsky's teaching-assessment dialectic and L2 education: The case for dynamic assessment. Mind, Culture, and Activity, 17(4), 312-30.

Poehner, M. E., \& van Compernolle, R. A. (2013). L2 development around test: Learner response processes and dynamic assessment. IRAL, 51(4), 353-71.

Sternberg, R. J., \& Grigorenko, E. L. (2002). Dynamic testing: The nature and measurement of learning potential. Cambridge: Cambridge University Press.

Tajeddin, Z., \& Tayebipour, F. (2012). The effect of dynamic assessment on EFL learners' acquisition of request and apology. Journal of Teaching Language Skills, 4(2), 87-118.

Vyogtsky, L. (1986). Language and Thought. USA: MIT.

Walqui, A. (2006). Scaffolding instruction for English language learners: A conceptual framework. International Journal of Bilingual Education and Bilingualism, 9(2), 159-80.

Wells, G. (1999). Dialogic inquiry: toward a sociocultural practice and theory of education. Cambridge: Cambridge University Press

Xiaoxiao, L., \& Yan, L. (2010). A case study of dynamic assessment in EFL process writing. Chinese Journal of Applied Lingusitics, 33(1), 24-40.

Zhang, Y. (2013). The theoretical construction of dynamic assessment mode in Chinese tertiary EFL writing class with online teaching and scoring system. CALL-EJ, 14(2), 38-50. 